\title{
TEKNOLOGI PENANGKAPAN DAN ANALISIS EKONOMI KM SARDINELA MENGGUNAKAN ALAT TANGKAP PUKAT CINCIN DI LAUT JAWA
}

\author{
Herry Riah Barus*) dan Agustinus Anung *)
}

\begin{abstract}
ABSTRAK
Usaha penangkapan dengan pukat cincindi perairan Laut Jawa pada umumnya belum menggunakan teknologi yang memadai sehingga efektivitasnya belum optimal yang ditandai dengan masih rendahnya produktivitas. Dalam upaya peningkatan efektivitas tersebut, telah dilakukan penelitian melalui pengoperasian kapal pukat cincin prototipe yaitu KM Sardinela 64 GT dengan kekuatan mesin 300 HP milik Balai Penelitian Perikanan Laut. Kapal tersebut dilengkapi antara lain GPS, fish finder, SSB, lampu pengumpul ikan dan rumpon. Pukat cincin yang digunakan mempunyai panjang $374 \mathrm{~m}$. Penelitian penangkapan dilakukan bersama-sama antara peneliti, teknisi dan nelayan. Hasil penelitian menunjukkan bahwa rata-rata produksi ikan adalah $19.912 \mathrm{~kg}$ per trip atau $2.096 \mathrm{~kg}$ per tawur dengan keuntungan Rp 4.757.701 per trip. Dari analisis biaya dan keuntungan, diketahui bahwa tingkat pengembalian investasi sebesar 42,9\% per tahun dengan jangka waktu 2,3 tahun. Dari sistem bagi hasil, masingmasing nelayan mendapat bagian antara Rp 58.015,- sampai Rp 174.015,-
\end{abstract}

\section{ABSTRACT: Fishing technology and economic analysis of MV Sardinella operation using purse seine in the Java Sea. By: Herry Riah Barus and Agustinus Anung.}

The appropriate technology on purse seine in the Java Sea has not been applied, therefore the optimal production and the fishermen income has not been achieved yet. In the purpose of increasing of effectivity on purse seine, RIMF carried out research on purse seine by using MV.Sardinela purse seiner (64 GT, 300 HP) equipped with GPS, Fish Finder, SSB, fish gathering lamp and FADs. Length of purse seine net is $374 \mathrm{~m}$. The fishing experiment was carried out by scientists, technicians and fishermen. The result showed that the average production was 19,912 $\mathrm{kg}$ per trip and the profit was Rp 4,757,701,-per trip The benefit cost analysis showed that the return on investment was $42,9 \%$ with pay back period of 2.3 years Sharing system between owner and fishermen showed that the income of each fishermen ranged from $R p 58,015$,- to $R p 174,015$,

\section{KEYWORDS: fishing technology, purse seine, Java sea.}

\section{PENDAHULUAN}

Perikanan pukat cincin (purse seine) di perairan Laut Jawa telah berkembang sejak awal 1970-an. Alat tangkap ini ditujukan untuk menangkap jenisjenis ikan pelagis. Sekitar $40 \%$ ikan pelagis yang didaratkan di pusat-pusat pendaratan ikan di Pantai Utara Jawa merupakan hasil tangkapan pukat cincin (Potier \& Petit, 1995). Fenomena tersebut menggambarkan betapa pentingnya peran perikanan pukat cincin di perairan Utara Jawa.

Sejak awal perkembangannya hingga sekarang, perikanan pukat cincin di perairan Utara Jawa telah banyak mengalami perkembangan, terutama yang menyangkut aspek teknologi penangkapannya. Perubahan tersebut antara lain pada ukuran kapal dan jaring yang digunakan. Dari segi ukuran kapal, perikanan pukat cincin di Utara Jawa dibedakan menjadi tiga tipe, yaitu perikanan pukat cincin mini, pukat cincin sedang dan pukat cincin besar (Potier \& Sadhotomo, 1995). Pada pukat cincin mini, ukuran panjang (L) kapal yang digunakan antara $12-18 \mathrm{~m}$, pukat cincin sedang mencapai $24 \mathrm{~m}$ dan pukat cincin besar lebih dari $24 \mathrm{~m}$.

Secara umum efektivitas penangkapan dengan pukat cincin di perairan Laut Jawa belum optimum dengan rata-rata hasil tangkapan pukat cincin sedang periode tahun 1987-1992 hanya mencapai $892,2 \mathrm{~kg}$ (512-1.688 kg) per tawur (Potier \& Petit, 1995). Dibanding rata-rata hasil tangkapan pukat cincin sedang yang beroperasi di perairan Teluk Moro (Filipina) mencapai $10.000 \mathrm{~kg}$ per tawur (Raharjo, 1993).

Rendahnya efektivitas pukat cincin yang beroperasi di perairan Utara Jawa dipengaruhi oleh banyak faktor, yang selama ini diduga sebagai penyebab utama adalah kinerja kapal

'Peneliti pada Balai Penelitian Perikanan Laut 
yang belum optimum. Hasil penelitian yang dilakukan oleh Bar (1988) menunjukkan bahwa salah satu masalah penting yang dihadapi kapalkapal kayu (termasuk kapal penangkap ikan) adalah yang menyangkut sistem mesin penggerak (propulsi) yang belum baik yang mengakibatkan kecepatan kapal rendah. Salah satu faktor yang sangat penting yang mempengaruhi efisiensi alat tangkap pukat cincin adalah kecepatan melingkarkan jaring saat tawur. Dengan demikian pada penangkapan dengan pukat cincin mutlak diperlukan kapal dengan kecepatan tinggi. Selain itu pada kapal-kapal pukat cincin yang telah berkembang, baru sedikit yang dilengkapi dengan alat-alat penting yang mampu menunjang efisiensi penangkapan. Alat-alat tersebut antara lain fish finder dan GPS (Global Positioning System).

Oleh karena itu Balai Penelitian Perikanan Laut (Balitkanlut) melakukan penelitian dengan KM Sardinela (64 GT, 300 HP) yaitu kapal pukat cincin ukuran sedang yang dioperasikan bersama antara peneliti dan teknisi serta nelayan. Kapal ini pada dasarnya adalah seperti kapal pukat cincin ukuran sedang yang selama ini telah berkembang namun dilakukan berbagai modifikasi. Modifikasi tersebut antara lain menyangkut penggunaan propulsi dengan kekuatan relatif besar, yaitu 300 HP. Dengan demikian kecepatan yang dihasilkan akan tinggi, yang merupakan faktor penting keberhasilan dalam penangkapan dengan pukat cincin. Selain itu KM Sardinela juga dilengkapi alat-alat penting sebagai pendukung efektivitas dan efisiensi pukat cincin, yaitu fish finder sebagai alat detektor gerombolan ikan dan GPS sebagi alat penentu posisi yang tepat.

Hasil yang diharapkan dari penelitian ini meliputi data dan informasi dari performansi teknis, kemampuan tangkap (hasil tangkapan per tawur) dan pendapatan serta keuntungan usaha termasuk pendapatan nelayan. Selain itu dapat dikemukakan beberapa penilaian usaha meliputi tingkat pengembalian dan jangka waktu pengembalian investasi.

\section{BAHAN DAN METODE}

Penelitian dilaksanakan antara bulan JuniNovember 1995 dengan KM Sardinela di perairan Timur Laut Pulau Bawean pada kedalaman 32-68 meter. KM Sardinela mempunyai dimensi utama panjang (L) 20,75 m, lebar (B) 5,80 m dan dalam (D) 2,23 $\mathrm{m}$ atau $64 \mathrm{GT}$, dengan mesin penggerak (M/E) $300 \mathrm{HP}$ dan generator (G/E) $15 \mathrm{HP}$ serta palka ikan 30 ton dengan sistem pengawetan es. Perlengkapan penting lain adalah fish finder (detektor gerombolan ikan) dan GPS (alat penentu posisi dan kecepatan yang bekerja berdasarkan satelit) serta $\mathrm{SSB}$ radio (alat komunikasi). Jaring pukat cincin yang digunakan mempunyai ukuran panjang $374 \mathrm{~m}$. Alat bantu penangkapan berupa rumpon dan lampu pengumpul ikan. Atraktan rumpon terbuat dari daun kelapa, sedangkan lampu pengumpul adalah lampu halogen sebanyak 12 buah dengan total kekuatan $4,8 \mathrm{~kW}$. Jaring pukat cincin dioperasikan (setting hauling) satu hari satu kali, yang dimulai saat menjelang pagi (pukul 04.00) hingga pagi hari (pukul 09.00). Data yang dikumpulkan adalah hasil tangkapan selama enam trip penangkapan.

Analisis ekonomi didasarkan pada rata-rata nilai hasil tangkapan ikan pada tiga trip yang memenuhi syarat. Berdasarkan analisis biaya dan keuntungan (cost and benefit) dari nilai hasil tangkapan tersebut diperoleh antara lain: keuntungan tahunan (annual financial profit), tingkat pengembalian investasi (rate of return) dan jangka waktu pengembalian investasi (payback period). Pendapatan antara pemilik dan nelayan didapatkan melalui perhitungan bagi hasil.

\section{HASIL DAN BAHASAN}

\section{Aspek Teknologi Penangkapan}

\section{Pengoperasian jaring}

Pada pengoperasian jaring pukat cincin diperlukan kecepatan kapal yang tinggi, karena efisiensi penangkapan dengan pukat cincin antara lain dipengaruhi oleh kecepatan melingkar jaring saat jaring ditawur. Tenaga mesin penggerak kapal yang besar menghasilkan kecepatan kapal yang tinggi. Hasil pengukuran terhadap kecepatan kapal dengan GPS diketahui bahwa rata-rata kecepatan lurus KM.Sardinela adalah 9,8 knot. Selain hal tersebut di atas, efisiensi pukat cincin juga dipengaruhi oleh kecepatan tertutupnya celah dari dua sisi jaring hingga membentuk kantong dengan cara menarik tali kolornya. Pada kapal-kapal pukat cincin medium dan besar, penarikan tali kolor jaring pukat cincin saat dioperasikan digunakan alat penarik yang lazim disebut 'gardan' yang tenaganya ditransfer dari mesin penggerak kapal. Sehingga penggunaan mesin dengan tenaga besar untuk penggerak kapal, juga berakibat langsung terhadap kekuatan gardan penarik tali kolor tersebut. Rata-rata waktu yang diperlukan untuk melingkarkan jaring dan menarik tali kolor dari 57 kali tawur selama penelitian adalah 2,97 menit dan 11,98 menit. Nilai tersebut masih lebih kecil dari umumnya kapal-kapal pukat cincin sejenis yang beroperasi di Laut Jawa, yaitu 3,0 menit dan 15 menit (Potier \& Petit, 1995). Dengan demikian 
peluang lolosnya ikan saat tawur dari pukat cincin KM Sardinela relatif kecil.

\section{Hasil tangkapan}

Indikator keberhasilan penangkapan ikan, salah satunya dilihat dari produktivitas alat tangkap yang dioperasikan. Dari enam trip (57 kali tawur) total tangkapan KM Sardinela mencapai $119.474 \mathrm{~kg}$ (ratarata $19.912 \mathrm{~kg} /$ trip dan $2.096 \mathrm{~kg} /$ tawur) (Tabel 1). Jumlah tersebut masih lebih tinggi dari rata-rata hasil tangkapan jaring pukat cincin sedang di perairan Utara Jawa yaitu $892,2 \mathrm{~kg} /$ tawur (Potier \& Sadhotomo, 1995). Dengan demikian secara teknis KM Sardinela cukup berhasil dalam melakukan operasi penangkapan. Jenis ikan yang tertangkap didominasi oleh jenis ikan layang (Decapterus spp.) $57,66 \%$. Jenis ikan lain yang juga tertangkap adalah
$(45,80 \%)$, sedangkan yang lain berturut-turut adalah: mesin Rp 46.000.000 (23,41\%), jaring Rp 45.500.000,- (23,16\%), alat navigasi dan perlengkapan lain Rp 15.000.000,- (7,63\%). Perkiraan daya tahan (nilai ekonomis) kapal dan mesin adalah 20 tahun, jaring lima tahun dan alat navigasi dan peralatan lainnya 10 tahun.

\section{Biaya}

Struktur biaya dalam mengoperasikan kapal pukat cincin per trip penangkapan dapat dibedakan menjadi dua, yaitu biaya tidak tetap (variable cost) dan biaya tetap (fixed cost). Biaya tidak tetap meliputi pembelian bahan bakar, es, air tawar, bahan makanan, perbaikan mesin serta jaring dan lainnya dengan total variable cost (TVC) Rp 6.323.000,- per trip. Sedangkan biaya tetap meliputi

Tabel 1. Jumlah trip, lamanya trip, hari efektif penangkapan, hasil tangkapan dan rata-rata hasil tangkapan per tawur (hari) KM Sardinela pada bulan Juni-November 1995.

Table 1. Number of trip, effective fishing days, catch yield and catch rate of $M V$ Sardinela in June-November 1995.

\begin{tabular}{ccccc}
\hline $\begin{array}{c}\text { Jumlah } \\
\text { trip } \\
\begin{array}{c}\text { No. of } \\
\text { Trip }\end{array}\end{array}$ & $\begin{array}{c}\text { Lama trip } \\
\text { (hari) } \\
\text { Duration of } \\
\text { trip (days) }\end{array}$ & $\begin{array}{c}\text { Hari efektif } \\
\text { penangkapan } \\
\text { Efective fishing } \\
\text { days }\end{array}$ & $\begin{array}{c}\text { Hasil } \\
\text { tangkapan } \\
\text { Catch yield } \\
\text { (kg) }\end{array}$ & $\begin{array}{c}\text { Rata-rata } \\
\text { tangkapan } \\
\text { (kg/tawur) } \\
\text { Catch rate } \\
\text { (kg/setting) }\end{array}$ \\
\hline 1 & 12 & 4 & 17,977 & 4,499 \\
2 & 11 & 5 & 13,200 & 2,640 \\
3 & 21 & 15 & 19,220 & 1,281 \\
4 & 18 & 11 & 25,570 & 2,324 \\
5 & 16 & 7 & 27,800 & 3,971 \\
6 & 27 & 15 & 15,687 & 1,046 \\
\hline Jumlah & 105 & 57 & 119,474 & 15,761 \\
Total & 17.5 & 9.5 & 19,912 & 2,096 \\
\hline Rata-rata & \multirow{2}{*}{\begin{tabular}{l} 
Average \\
\hline
\end{tabular}}
\end{tabular}

kembung (Rastrelliger spp.) 22,60\% dan japuh (Dussumieria spp.) 10,60\% (Tabel 2).

\section{Aspek Ekonomi}

\section{Investasi}

Investasi yang diperlukan pada penangkapan dengan pukat cincin meliputi kapal dan mesinnya, jaring, alat bantu penangkapan dan peralatan navigasi (Tabel 3). Nilai masing-masing komponen tersebut di atas adalah sebagai berikut: kapal mempunyai nilai tertinggi yaitu $\operatorname{Rp} 90.000 .000$,- biaya tambat labuh, surat-surat kapal dan biaya penyusutan dengan total fixed cost (TFC) Rp 1.244.365,- per trip. Dengan demikian total biaya seluruhnya (Total Financial Cost) KM Sardinela per trip adalah Rp 7.568.365,- (Tabel 4).

\section{Analisis ekonomi}

Analisis ekonomi didasarkan pada biaya dan hasil penjualan ikan tangkapan serta keuntungannya. Nilai hasil penjualan sendiri merupakan jumlah hasil lelang ikan dikurangi biaya administrasi dan biaya kegiatan lelang. Sedangkan keuntungan 
Tabel 2. Komposisi jenis ikan yang tertangkap oleh KM Sardinela bulan Juni-November 1995. Table 2. Fish catch composition caught by MV Sardinela in June-November 1995.

\begin{tabular}{llc}
\hline $\begin{array}{c}\text { Nama Indonesia } \\
\text { Indonesian name }\end{array}$ & \multicolumn{1}{c}{$\begin{array}{c}\text { Nama ilmiah } \\
\text { Scientific name }\end{array}$} & $\begin{array}{c}\text { Persentase } \\
\text { Percentage } \\
\text { (\%) }\end{array}$ \\
\hline Layang & Decapterus spp. & 57.66 \\
Kembung & Rastrelliger spp. & 22.60 \\
Japuh & Dussumieria spp. & 10.60 \\
Layur & Lepturacantus spp. & 1.58 \\
Cumi-cumi & Loligo spp. & 1.43 \\
Kelompok selar & Selar spp. & 0.73 \\
Tongkol & Auxis spp. & 0.74 \\
Lain-lain & Lain-lain (Others) & 4.66 \\
\hline Jumlah (Total) & & 100.00 \\
\hline
\end{tabular}

Tabel 3. Investasi usaha penangkapan KM Sardinela.

Table 3. Fishing investment of MV Sardinela.

\begin{tabular}{lccc}
\hline $\begin{array}{c}\text { Komponen investasi } \\
\text { Componen of } \\
\text { investment }\end{array}$ & $\begin{array}{c}\text { Biaya } \\
\text { Value } \\
(\mathbf{R p})\end{array}$ & $\begin{array}{c}\text { Persentase } \\
\text { Percentage } \\
\mathbf{( \% )}\end{array}$ & $\begin{array}{c}\text { Depresiasi } \\
\text { Depreciation } \\
(\mathbf{R p})\end{array}$ \\
\hline Kapal (Boat) & $90,000,000$ & 45.80 & 250,000 \\
Mesin (Engine) & $46,000,000$ & 23.41 & 127,777 \\
Jaring (Nets) & $45,500,000$ & 23.16 & 505,555 \\
Perlengkapan (Equipment) & $15,000,000$ & 7.63 & 38,333 \\
\hline Jumlah (Total) & $196,500,000$ & 100.00 & 966,665 \\
\hline
\end{tabular}

merupakan nilai hasil penjualan dikurangi total biaya. Hasil analisis ekonomi dari usaha penangkapan dengan KM Sardinela di sajikan pada Tabel 5.

Dari Tabel 5 tersebut dapat dilihat bahwa keuntungan usaha penangkapan dengan KM Sardinela mencapai Rp 4.757.707,- per trip atau Rp 85.638.618,- per tahun (18 trip). Selain itu dapat dilihat pula mengenai nilai tingkat pengembalian investasi (R.R. unadjusted) sebesar 38,58\% dan (R.R. adjusted) sebesar $43,66 \%$ atau dengan penghitungan pengembalian investasi (return on investment, R.O.I.) sebesar $42,90 \%$ dan jangka waktu pengembalian modal (payback period) 2,3 tahun. Dengan demikian hasil analisis tersebut menunjukkan bahwa secara ekonomis, pengusahaan KM Sardinela adalah menguntungkan.

\section{Bagi hasil}

Pada perikanan pukat cincin, sistem bagi hasil pendapatan sangat bervariasi di antara perusahaan- perusahaan penangkapan yang satu dengan yang lainnya. Pada KM Sardinela, sistem yang diterapkan adalah: rata-rata hasil penjualan dikurangi biaya lelang per trip adalah Rp 12.323.066,- (Tabel 5). Dari jumlah tersebut dikurangi biaya operasi (VC) sebesar Rp 6.324.000,- dan untuk nelayan berupa laukan sebesar 5\% yaitu Rp 369.781,-- serta insentif sebesar $2,5 \%$ yaitu $R p$ 308.151,- sehingga penghasilan bersih I adalah Rp 5.304.134,-. Dari penghasilan bersih I, dikurangi lagi cadangan untuk nelayan sebesar 5\% yaitu Rp 266.202,-; pengurus $5 \%$ yaitu Rp 266.202 ,- dan pendapatan untuk pemilik $15 \%$ yaitu $R p 798.620$,- sehingga didapat penghasilan bersih II sebesar Rp 3.993.102,-. Dari penghasilan bersih II selanjutnya dibagi dua antara nelayan dan pemilik masing-masing 50\%. Dengan demikian pendapatan masing-masing adalah Rp 1.996.551,-- Total pendapatan yang diterima nelayan adalah Rp 2.610.689,.. Dari jumlah tersebut, pendapatan terrendah seorang nelayan (kelasi) adalah 1/45 bagian yaitu Rp 68.015,- dan 
Tabel 4. Rata-rata struktur biaya per trip usaha penangkapan dengan KM Sardinela. Table 4. Average cost structure of MV.Sardinela fishing per trip.

\begin{tabular}{|c|c|c|c|}
\hline & Item & \multicolumn{2}{|c|}{$\begin{array}{c}\text { Biaya (Value) } \\
\text { (Rp) }\end{array}$} \\
\hline \multicolumn{4}{|c|}{ Biaya Tidak Tetap (Variable Cost) } \\
\hline - & Bahan bakar (Fuel and lubricating oil) & \multicolumn{2}{|c|}{$2,100,000$} \\
\hline - & Es batu (Ice) & \multicolumn{2}{|c|}{$1,450,000$} \\
\hline - & Makanan (Foods) & \multicolumn{2}{|c|}{$1,300,000$} \\
\hline & Pemeliharaan (Maintenance) & \multicolumn{2}{|l|}{800,000} \\
\hline - & Biaya lain-lain (Miscellaneous) & \multicolumn{2}{|l|}{674,000} \\
\hline & Jumlah Biaya Tidak Tetap (Total Variable Cost) & & $6,324,000$ \\
\hline \multicolumn{4}{|c|}{ Biaya tetap (Fixed Cost) } \\
\hline & Lisensi, docking (Licenses, docking) & 277,700 & \\
\hline \multicolumn{4}{|c|}{ - Depresiasi (Depreciation) } \\
\hline & Jumlah Biaya Tetap (Total Fixed Cost) & & $1,244,356$ \\
\hline Jur & lah biaya (Total Financial Cost) & & $7,568,365$ \\
\hline
\end{tabular}

Tabel 5. Hasil tangkapan, pendapatan, biaya, dan keuntungan per trip usaha penangkapan K.M Sardinela.

Table 5. Catch, revenue, cost and profit per fishing trip of MV Sardinela.

\begin{tabular}{lcc}
\hline \multicolumn{1}{c}{ Item } & $\begin{array}{c}\text { Biaya per trip } \\
\text { Value per trip }\end{array}$ & $\begin{array}{c}\text { Biaya per tahun } \\
\text { Value per year }\end{array}$ \\
\hline Jumlah tangkapan (Total catch) (kg) & 19,912 & 358,461 \\
Jumlah pengembalian (Total revenue) (Rp) & $12,326,066$ & $221,869,188$ \\
Jumlah pembiayaan (Total financial cost) (Rp) & $7,568,365$ & $136,230,570$ \\
Biaya keuntungan (Financial profit) (Rp) & $4,757,701$ & $85,638,618$ \\
R.R. (unadjusted, \%) & - & 38.58 \\
R.R. (adjusted, \%) & - & 43.66 \\
Present value (RP) & - & $458,423,522$ \\
pajak (interest) 18\% & & \\
Jangka waktu pengembalian (tahun) & - & 2.3 \\
Payback period (years) & & 42.9 \\
Tingkat pengembalian investasi & & \\
R.O.I (\%) & & \\
\hline
\end{tabular}

tertinggi (nahkoda) adalah tiga kali $1 / 45$ bagian yaitu Rp 174.045,-. Sedangkan total pendapatan pemilik Rp 2.432.577,-.
Dari hasil bagi keuntungan yang didapat, masing-masing nelayan memperoleh penghasilan sebesar Rp 57.015,- hingga Rp174.045,- per trip. 


\section{KESIMPULAN DAN SARAN}

\section{Kesimpulan}

Modifikasi teknis yaitu penggunaan mesin penggerak dengan kekuatan relatif tinggi ( $300 \mathrm{HP})$, penggunaan fish finder dan GPS pada KM Sardinela mampu menaikkan produktivitas hasil tangkapan hingga $2.096 \mathrm{~kg} /$ tawur $(19.912 \mathrm{~kg} /$ trip$)$.

Berdasarkan analisis biaya dan keuntungan (cost and benefit), keuntungan per trip penangkapan adalah $\mathrm{Rp} 4.757 .701,-$. Sedangkan tingkat pengembalian investasi (return of investment) sebesar $42,9 \%$ dan jangka waktu pengembalian investasi (payback period) selama 2,3 tahun.

Dari hasil bagi keuntungan yang didapat, masing-masing nelayan memperoleh penghasilan sebesar Rp 57.015,- hingga Rp174.045,- per trip.

\section{Saran}

Pada pembangunan kapal-kapal pukat cincin medium, agar kekuatan (HP) mesin penggerak yang digunakan disesuaikan dengan ukuran kapal (GT) yang dibangun. Dengan demikian akan menghasilkan kapal dengan kecepatan yang memadai untuk penangkapan dengan pukat cincin.

Pada kapa-kapal yang telah ada, penambahan alat-alat seperti fish finder dan GPS sangat disarankan demi efektivitas penangkapan.

\section{DARTAR PUSTAKA}

Bar, Dop R. 1988. Pengenalan Pembuatan Kapal Kayu Moderen Laminasi. LKI, Depertemen Perindustrian R.I. Jakarta, 23-.

Potier, M. and Sadhotomo, B. 1995. Seiner fisheries in Indonesia, BIODYNEX of the Small Pelagic Fishes in the Java Sea, Jakarta, 49-66.

Potier, M. and Petit, D. 1995. Fishing strategies and tactic in the Javanese seiner fisheries, BIODINEX of the Small Pelagic Fishes in Java Sea, Jakarta. 171-184.

Raharjo, P. 1993. Penangkapan ikan pelagis besar dengan menggunakan purse seine di Perairan Moro Gulf (Philipina), Prosiding Simposium Perikanan Indonesia I, Jakarta. 392-401 